\title{
Immunohistochemical expression of Bcl-2 in benign and malignant salivary gland tumors
}

\author{
Manjunatha B S ${ }^{1}$, Kumar G S ${ }^{2}$, Vandana Raghunath ${ }^{3}$
}

${ }^{1}$ BDS, MDS, FAGE Reader in Oral Pathology \& Microbiology, K M Shah Dental College \& Hospital, Pipariya-391760, Waghodia (T), Vadodara (D), Gujarat (S), India

${ }^{2}$ BDS, MDS, FAGE Dean, Professor \& Head Dept Oral and Maxillofacial Pathology, K.S.R.Institute of Dental Sciences \& Research, K.S.R.Kalvi Nagar, Tiruchengode-637209, Tamil Nadu, India

${ }^{3}$ BDS, MDS Professor \& Head, Dept Oral and Maxillofacial Pathology, Narayana Dental College and Hospital, Nellore, India

Correspondence:

K M Shah Dental College \& Hospital,

Pipariya-391760,

Waghodia (T), Vadodara (D),

Gujarat (S), INDIA

drmanju26@hotmail.com

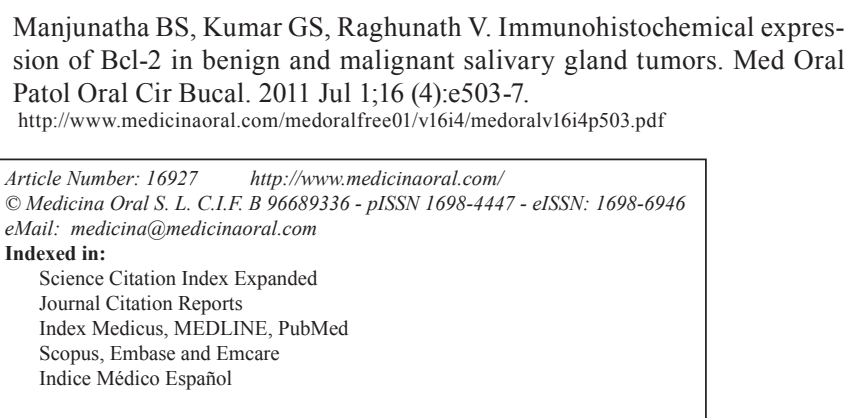

\begin{abstract}
Objectives: The present study was undertaken to assess and compare the immunohistochemical expression of Bcl-2 in selected benign and malignant salivary gland tumors.

Study Design: A total of 50 cases of buffered formalin-fixed, paraffin embedded tissues of previously diagnosed cases of benign and malignant salivary gland tumors from the archives of Department of Oral and Maxillofacial Pathology and Microbiology, SDM College of Dental Sciences and Hospital, Dharwad, India, were taken for the study. The immunohistochemical staining procedure was performed using monoclonal anti Bcl-2 antibody, as directed by the manufacturer.

Results: Thirty six cases (72\%) out of 50 cases showed a positive expression for Bcl-2. Benign salivary gland tumors showed a positive expression in 8 out of 14 cases $(\sim 57 \%)$ and malignant salivary gland tumors in 28 out of 36 cases $(\sim 78 \%)$. The staining was intense in the normal lymph node, which is used as a positive control. Bcl-2 expression was seen in both benign and in malignant salivary gland tumors taken for the study except in "canalicular adenoma".

Conclusion: The immunohistochemical expression of Bcl-2 was greater and more intense in malignant salivary gland neoplasms, suggesting a high survival rate of tumor cells in malignant neoplasms.
\end{abstract}

Key words: Bcl-2, salivary gland neoplasms, apoptosis, pleomorphic adenoma, adenoid cystic carcinoma, mucoepidermoid carcinoma. 


\section{Introduction}

Salivary gland neoplasms are relatively uncommon and represent $<2 \%$ of all tumors in humans, occurring both in major and minor glands. They possess a wide variety of histologic appearances and biologic behavior (1).

Apoptosis is a distinct process of cell death that is responsible for deletion of aged, injured and altered cells in normal and in certain specific pathologies like neoplasia $(2,3)$.

Bcl-2 is the first gene shown to be involved in apoptosis and was regarded as a proto-oncogene that suppresses the cell death rather than stimulating cell proliferation $(4,5)$. The human $\mathrm{Bcl}-2$ protein is an intracellular, integral membrane protein with a molecular weight of about $26 \mathrm{kD}$.

Bcl-2 expression has been studied in oral epithelial dysplasia, oral submucous fibrosis and oral squamous cell carcinoma and its expression showed increasing with the severity of dysplasia and decreased expression in differentiation of oral carcinoma (6,7). Bcl-2 expression was shown to be downregulated in the malignant transformation of ameloblastoma (8). Studies of Bcl-2 expression in salivary gland tumors are limited and largely confined to few tumors and also in small number of cases.

\section{Materials and Methods}

A total of 50 cases of buffered formalin-fixed, paraffin embedded tissues of previously diagnosed cases of benign and malignant salivary gland tumors were selected from the archives of Department of Oral and Maxillofacial Pathology and Microbiology, SDM College of Dental Sciences and Hospital, Dharwad, India, to assess the immunohistochemical expression of Bcl-2.

The benign tumors such as pleomorphic adenoma ( 9 cases), myoepithelioma (3 cases), and canalicular adenoma ( 2 cases) and malignant tumors such as adenoid cystic carcinoma (majority of them had a mixture of cribriform and tubular patterns) (ACC) (21 cases), mucoepidermoid carcinoma (MEC) (11 cases), and adenocarcinoma not otherwise specified (NOS) (4 cases) were taken for the study.

Immunohistochemical staining procedure: Serial sections of $4 \mu \mathrm{m}$ thickness were taken on silanised slides (S 4651, SIGMA DIAGNOSTICS, USA) meant for immunohistochemistry. The sections were deparaffinised in xylene for 5 minutes, hydrated through graded alcohols for 3 minutes each and washed with Tris buffer saline (TBS). Endogenous peroxidase activity was blocked with $3 \% \mathrm{H}_{2} \mathrm{O}_{2}$ in methanol for 10 minutes. The antigen retrieval was performed by heating the slides in a pressure cooker containing $10 \mathrm{mM}$ citrate buffer (pH 6.0) solution for 5 minutes. The sections were incubated with the primary antibody, anti Bcl-2 oncoprotein (Monoclonal mouse anti-human, clone 124, DAKO,
CA, USA) for 3 to 4 hours at $30^{\circ} \mathrm{C}$ in a humidifying chamber. The subsequent procedures were done according to manufacturer's protocol. The standard streptavidin - biotin - peroxidase complex method was done to bind primary antibody with the use of a LSAB + system universal kit (K0679). The reaction products were visualized using $0.3 \%$ diaminobenzidine solution. The specificity of immunohistochemical staining was noted by replacing the primary antibody with TBS (negative control).

Finally, the slides were counterstained with Mayer's haematoxylin and mounted using a non-aqueous mounting medium.

Evaluation: The sections were evaluated for the staining and the intensity of Bcl-2 expression. Observations were made on the basis of intensity of cytoplasmic staining which was either invariably finely granular or rarely homogenous in the majority of the tumor cells. The normal lymph node was used as positive control, which showed intense staining in the mantle zone. This was compared with positive tumor cases for grading purposes. The intensity was graded in all the cases with 0 representing no staining, 1, 2 and 3 to represent mild, moderate and intense staining respectively. Though judging intensity is regarded as subjective, care was taken to reduce the subjectivity by 3 independent observations (two other observers by senior faculty members in the department) and by intra lesional comparison with lymphocytes along with positive control, which were intensely positive for Bcl-2.

The results obtained were taken for statistical analysis by using 'Chi-Square test' and ' $\mathrm{Z}$ proportionality test'.

\section{Results}

The Bcl-2 showed a positive immunostaining in 36 cases $(72 \%)$ out of 50 , of which the benign tumors showed positive expression in $8 / 14(\sim 57 \%)$ and malignant tumors in 28/36 ( 78\%) cases (Table 1).

The expression and the intensity of staining in individual tumors are summarized in table 2. Majority of adenoid cystic carcinomas were consistently positive for Bcl-2. Different histologic types of adenoid cystic carcinomas (cribriform and tubular patterns) showed a positive expression for Bcl-2 (Fig. 1), but varied in the intensity of staining.

Among the positive cases of mucoepidermoid carcinoma, most of the mucous cells were negative except for one case, which showed intense homogenous staining. The epidermoid and intermediate cells were usually positive (Fig. 2).

No statistical significance was observed with regard to intensity of Bcl-2 expression in benign and malignant tumors $\left(\chi^{2}=3.7217\right)$.

Since the sample of cases in each of the tumor types (except for adenoid cystic carcinoma) were limited and 
Table 1. Bcl-2 expression in different Benign and Malignant Salivary Gland Tumors.

\begin{tabular}{|c|l|c|c|c|}
\hline Serial No & \multicolumn{1}{|c|}{ Lesion } & No of Cases & Positive cases & \% of Bcl-2 positivity \\
\hline 1 & Pleomorphic Adenoma & 09 & 05 & $55 \%$ \\
\hline 2 & Myoepithelioma & 03 & 03 & $100 \%$ \\
\hline 3 & Canalicular Adenoma & 02 & 00 & $0 \%$ \\
\hline 4 & Adenoid cystic carcinoma & 21 & 21 & $100 \%$ \\
\hline 5 & Mucoepidermoid carcinoma & 11 & 05 & $45 \%$ \\
\hline 6 & Adenocarcinoma NOS & 04 & 02 & $50 \%$ \\
\hline & Total & 50 & 36 & $72 \%$ \\
\hline
\end{tabular}

Table 2. Intensity of Bcl-2 expression in various Benign and Malignant Salivary gland Tumors.

\begin{tabular}{|c|l|c|c|c|c|}
\hline \multirow{2}{*}{$\begin{array}{c}\text { Serial } \\
\text { No }\end{array}$} & \multicolumn{1}{|c|}{ Lesion } & \multirow{2}{*}{$\begin{array}{c}\text { No of } \\
\text { positive cases }\end{array}$} & \multicolumn{3}{|c|}{ Staining intensity } \\
\cline { 4 - 6 } & & 05 & 5 & 0 & 0 \\
\hline 1 & Pleomorphic Adenoma & 03 & 2 & 0 & 1 \\
\hline 2 & Myoepithelioma & 21 & 7 & 6 & 8 \\
\hline 3 & Adenoid cystic Carcinoma & 05 & 3 & 1 & 1 \\
\hline 4 & Mucoepidermoid Carcinoma & 02 & 1 & 0 & 1 \\
\hline 5 & Adenocarcinoma & 36 & 18 & 7 & 11 \\
\hline
\end{tabular}

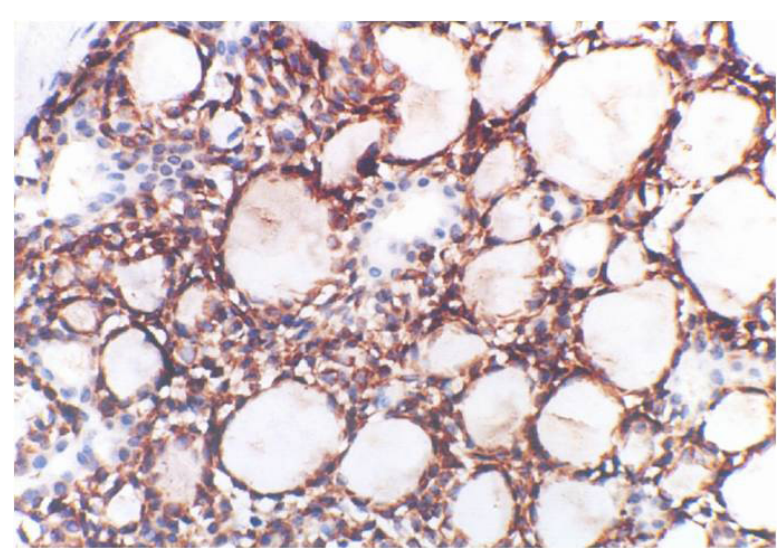

Fig. 1. Photomicrograph showing intense Bcl-2 expression in cribriform pattern of ACC (250X).

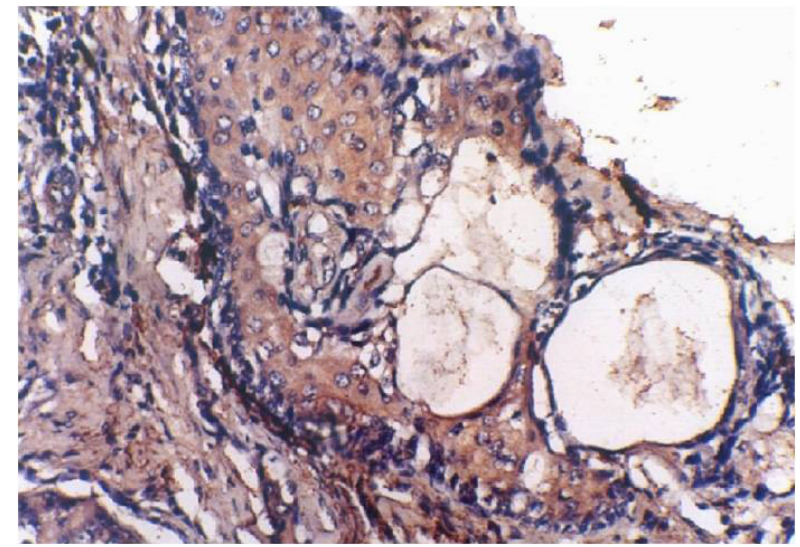

Fig. 2. Photomicrograph showing intense Bcl-2 expression in epidermoid cells in MEC (250X). 
varied greatly in the staining intensity of the positive cases, no meaningful statistical analysis was rendered. There's not much difference in the intensity of expression of Bcl-2 in all 21 cases of adenoid cystic carcinoma.

\section{Discussion}

Bcl-2 proto-oncogene, endowing B cells with a selective survival advantage that promotes their neoplastic expansion. The concept that defective programmed cell death contributes to malignancy was established by studies of Bcl-2, representing a major step forward in current understanding of tumorigenesis. Experimental therapies targeting Bcl-2 family proteins are currently in clinical testing have increased hopes that a new class of anticancer drugs may be near (9).

Bcl-2 expression is seen in many oral lesions like epithelial dysplasia and carcinoma, benign and malignant ameloblastomas, dentigerous and odontogenic keratocysts and also in glandular odontogenic cysts $(6,7,10,11)$.

Expression of Bcl-2 is highly variable in epithelial malignancies. Bcl-2 expression is linked to cell type and degree of differentiation. Other factors such as viral infection may also contribute to high levels of Bcl-2 in epithelial malignancies (5).

Bcl-2 has been studied in benign salivary tumors such as pleomorphic adenoma, myoepithelioma, Warthin's tumor and oncocytoma and in malignant salivary gland tumors $(12,13)$.

Very recent study on Bcl-2 oncoprotein in Warthin's tumor suggested a protective role of tumor cells from apoptosis to maintain their survival but not to increase their malignant potentiality. Elevated Bcl-2 expression was related to the possible protection against apoptosis. Ninety percent of cases (18 out of 20 cases) showed positive expression and both layers of the neoplastic epithelium (basal and luminal cells) showed positive immunoreactivity, with cytoplasmic localization, surrounded by a negatively stained stroma (14).

The increased expression of Bcl-2 in epidermoid cells of MEC can be correlated with increased survival rate of these cells and tumors with predominance of these cells. A recent report of Bcl-2 expression in MEC by Yin et al. (15) concluded that Bcl-2 is one of the potentially useful markers for survival in patients with MEC in minor salivary glands.

The lack of Bcl-2 expression in these cells may be linked to the degree of differentiation. Terminal differentiated cells like the mucous cells, normal acinar cells, salivary gland duct cells also do not express Bcl-2, but basal cells of the normal oral epithelium express Bcl-2. The mucous and intermediate cells were positive in one case.

The intense localization of $\mathrm{Bcl}-2$ expression was found in outer cells of tubular pattern, peripheral cells in solid pattern and the luminal cells in cribriform pattern.

In the present study, all the 21 cases $(100 \%)$ of adenoid cystic carcinoma showed positivity. This was similar to the earlier findings $(12,16)$. However, the expression of Bcl-2 in ACC, in other studies was $30 \%$ and $46.2 \%$ $(17,18)$.

The tumor ductal and myoepithelial cells in the various patterns of ACC were positive for Bcl-2. The expression of Bcl-2 in these cells can be linked to the lesser degree of differentiation compared to normal acinar cells and ductal cells of salivary glands. The Bcl-2 positive cells are involved in different pattern formation of ACC (Fig. $1)$.

Among the four cases of adenocarcinoma two were positive for Bcl-2 expression. One case showed focal intense positivity and the other was mildly positive. Our findings compares favorably with the only other study attributes loss of expression due to differentiation of basaloid cells (19).

All three cases of myoepithelioma showed positive Bcl-2 expression (Fig. 3), and Pammer et al. (12), who observed a focal expression in one and a negative expression in the other. The positive expression shows that tumor cells in the myoepithelioma retain the ability to form different stromal components as seen in pleomorphic adenoma.

Both the cases of canalicular adenoma showed negative expression for $\mathrm{Bcl}-2$, as these can be considered to be terminal differentiated tumor cells. Medline search did not reveal any study on Bcl-2 expression in 'canalicular adenoma'.

Soini et al. (13) compared Bcl-2 expression in pleomorphic adenomas and in malignant salivary gland tumors comprising of mainly ACC and MEC, found $100 \%$ positivity in pleomorphic adenoma and $64 \%$ positivity in malignant tumors. In contrast, our study showed a similar but somewhat higher expression in similar malig-

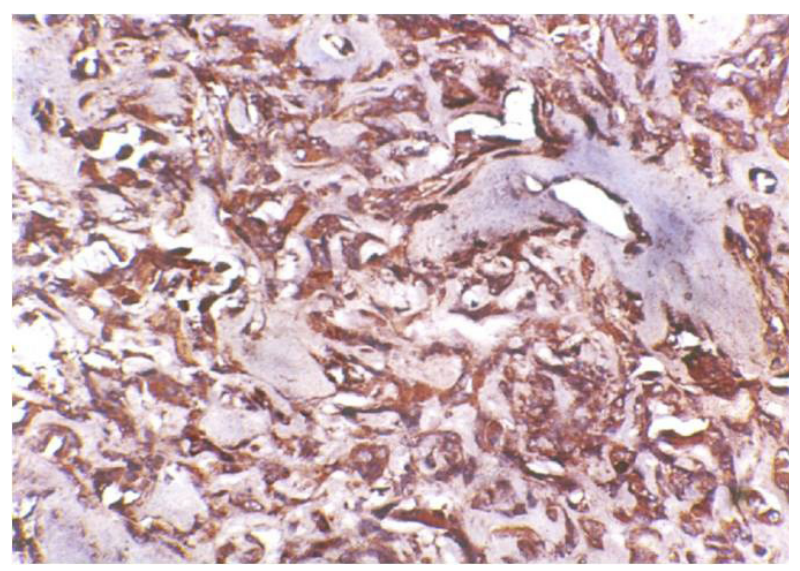

Fig. 3. Photomicrograph showing intense Bcl-2 expression in Myoepithelioma (250X). 
nant salivary gland tumors $(72 \%)$ and lesser expression in pleomorphic adenoma. Thus the cell survival rate is generally higher in malignant neoplasms than benign neoplasms. These observed differences in benign and malignant salivary gland neoplasms are of narrow range, which lack statistical significance. The lack of expression in pleomorphic adenoma may be attributed to the great variability in degree of epithelial cell differentiation.

There was no statistical significance in the expression or in the intensity between benign and malignant salivary gland tumors. Ductal cells and myoepithelial cells were positive in all types of ACC, myoepithelial cells in myoepithelioma and most of the epidermoid cells in MEC. The terminally differentiated tumor cells of MEC and ductal cells of canalicular adenoma like, the normal acinar cells and ductal cells of salivary glands were negative. $\mathrm{Bcl}-2$ expression in pleomorphic adenoma is variable due to the degree of differentiation.

\section{Conclusion}

Bcl-2 expression was seen in all benign salivary gland tumors except canalicular adenoma. The study appears to be the first one in canalicular adenoma. A higher degree of Bcl-2 expression is seen in malignant salivary gland tumors (78\%) than in benign tumors (57\%). This variable expression may be suggestive of a different susceptibility rate of tumor cells to apoptosis or 'programmed cell death'.

It is well established fact that morphology or appearance of cells remains the mainstay in diagnosis of salivary gland tumors. But, the immunohistochemistry is a valuable adjuvant in the diagnosis of malignant tumors of salivary gland origin as these have a very diverse histology. Studies of a larger sample with a wide variety of benign as well as malignant salivary gland tumors comprising of all subtypes or variants of tumors are required to understand the significance of Bcl-2 expression in the prognosis as well as clinical outcome for the future generations.

\section{References}

References with links to Crossref - DOI

1. Van der Wal JE, Leverstein H, Snow GB, Kraaijenhagen HA, Van der Waal I. Parotid gland tumors: histologic reevaluation and reclassification of 478 cases. Head Neck. 1998;20:204-7.

2. Kerr JF, Winterford CM, Harmon BV. Apoptosis. Its significance in cancer and cancer therapy. Cancer. 1994 Apr 15;73(8):2013-26. Review. Erratum in: Cancer 1994;73:3108

3. Langlois NE, Eremin O, Heys SD. Apoptosis and prognosis in cancer: rationale and relevance. J R Coll Surg Edinb. 2000;45:211-9.

4. Lu QL, Poulsom R, Wong L, Hanby AM. Bcl-2 expression in adult and embryonic non-haematopoietic tissues. J Pathol. 1993;169:431-7. 5. Lu QL, Abel P, Foster CS, Lalani EN. bcl-2: role in epithelial differentiation and oncogenesis. Hum Pathol. 1996;27:102-10.

6. Singh BB, Chandler FW Jr, Whitaker SB, Forbes-Nelson AE. Immunohistochemical evaluation of bcl-2 oncoprotein in oral dysplasia and carcinoma. Oral Surg Oral Med Oral Pathol Oral Radiol Endod. 1998;85:692-8.
7. Teni T, Pawar S, Sanghvi V, Saranath D. Expression of bcl-2 and bax in chewing tobacco-induced oral cancers and oral lesions from India. Pathol Oncol Res. 2002;8:109-14.

8. Kumamoto H, Ooya K. Immunohistochemical analysis of bcl-2 family proteins in benign and malignant ameloblastomas. J Oral Pathol Med. 1999;28:343-9.

9. Reed JC. Bcl-2-family proteins and hematologic malignancies: history and future prospects. Blood. 2008 Apr 1;111(7):3322-30. Review. Erratum in: Blood. 2008;112:452.

10. Mitsuyasu T, Harada H, Higuchi Y, Kimura K, Nakamura N, Katsuki $\mathrm{T}$, et al. Immunohistochemical demonstration of bcl-2 protein in ameloblastoma. J Oral Pathol Med. 1997;26:345-8.

11. Tosios KI, Kakarantza-Angelopoulou E, Kapranos N. Immunohistochemical study of bcl-2 protein, $\mathrm{Ki}-67$ antigen and $\mathrm{p} 53$ protein in epithelium of glandular odontogenic cysts and dentigerous cysts. J Oral Pathol Med. 2000;29:139-44.

12. Pammer J, Horvat R, Weninger W, Ulrich W. Expression of bcl-2 in salivary glands and salivary gland adenomas. A contribution to the reserve cell theory. Pathol Res Pract. 1995;191:35-41.

13. Soini Y, Törmänen U, Pääkkö P. Apoptosis is inversely related to bcl-2 but not to bax expression in salivary gland tumours. Histopathology. 1998;32:28-34.

14. Abd-Elhamid ES, Elshafei MM. Immunohistochemical localization of mdm-2, p27Kipl and bcl-2 in Warthin's tumor of the parotid gland. Diagn Pathol. 2009;4:14

15. Yin HF, Okada N, Takagi M. Apoptosis and apoptotic-related factors in mucoepidermoid carcinoma of the oral minor salivary glands. Pathol Int. 2000;50:603-9.

16. Yáñez M, Roa I, García M, Ibacache G, Villaseca M. [Bcl-2 gene protein expression in salivary gland tumors]. Rev Med Chil. 1999;127:139-42.

17. Fujita S, Shibata Y, Takahashi H, Tsuda N. Apoptosis-induced and -suppressed cells in salivary gland adenoid cystic carcinoma: correlation with histological growth patterns. Oral Dis. 1999;5:11722

18. Jia L, Esguerra RL, Tang X, Yin H, Sakamoto K, Okada N, et al. Prognostic value of apoptosis and apoptosis-associated proteins in salivary gland adenoid cystic carcinoma. Pathol Int. 2004;54:217-23. 19. Nagao T, Sugano I, Ishida Y, Hasegawa M, Matsuzaki O, Konno A, et al. Basal cell adenocarcinoma of the salivary glands: comparison with basal cell adenoma through assessment of cell proliferation, apoptosis, and expression of p53 and bcl-2. Cancer. 1998;82:439-47.

\section{Acknowldgements}

Authors wish to thank Dr. C. Bhasker Rao, Vice-President, Dental Council of India, New Delhi and Ex Dean, SDM College of Dental Sciences and Hospital, Sattur, Dharwad, INDIA, for all his support during this study. 